\title{
Estudo de palinofácies na sucessão rica em matéria orgânica da Formação Tremembé no poço TMB-3-SP (Oligoceno da Bacia de Taubaté)
}

\author{
Elayne Cristina Andrade de Sousa \\ Maas ${ }^{1 *}$ \\ Marco Brito \\ Sérgio Bergamaschi ${ }^{1}$ \\ Joalice de Oliveira Mendonça ${ }^{2}$ \\ 1 Departamento de Estratigrafia e Paleontologia \\ Faculdade de Geologia \\ Universidade do Estado do Rio de Janeiro \\ Rua São Francisco Xavier 524 \\ Maracanã \\ Rio de Janeiro RJ Brasil \\ CEP 20550-013 \\ ${ }^{2}$ Laboratório de Palinofácies \& Fácies Orgânica \\ Departamento de Geologia/IGEO/CCMN \\ Universidade Federal do Rio de Janeiro \\ Av. Athos da Silveira Ramos, 274 \\ Ilha do Fundão \\ Rio de Janeiro RJ Brasil \\ CEP 21949-900 \\ *autor correspondente: \\ elcristas@hotmail.com
}

\begin{abstract}
RESUMO
Com o objetivo de mostrar como a parte superior da Formação Tremembé evoluiu em termos de tipos de matéria orgânica e de paleoambiente foram analisadas palinofácies de 20 amostras do poço TMB-3-SP e revisitados dados sedimentológicos e geoquímicos de mesmas amostras. A associação dos dados de palinofácies com os dados de carbono orgânico total, índice de hidrogênio e sedimentológicos possibilitou subdividir a seção estudada em nove unidades, denominadas de 1 a 9 , da base para o topo da parte superior da Formação Tremembé. As unidades 1, 3, 5, 7 e 9 representam fases de lâmina de água baixa no lago, enquanto que as unidades $2,4,6$ e 8 correspondem a fases de lâmina de água alta no lago, testemunhando a unidade 6 o período com lâmina de água mais espessa e de maior expansão do lago. As fases de lâmina de água baixa no lago, possuem menores concentrações de matéria orgânica amorfa fluorescente e predomínio de algas do gênero Pediastrum sobre algas do gênero Botryococcus. Em contraste com as fases de lâmina de água alta no lago, com maiores concentrações de matéria orgânica amorfa fluorescente e predomínio de algas do gênero Botryococcus sobre algas do gênero Pediastrum. Para além de contribuir ao conhecimento da distribuição estratigráfica das características microscópias da matéria orgânica ao longo da parte superior da Formação Tremembé na região central da Bacia de Taubaté, os novos dados constituem importantes indicadores paleoambientais.
\end{abstract}

Palavras-chave: Bacia de Taubaté, Formação Tremembé, palinofácies.

\section{ABSTRACT}

In order to show how the upper part of the Tremembe Formation evolved in terms of organic matter and paleoenvironment types, palynofacies of 20 samples from the TMB-3-SP well were analyzed and sedimentological and geochemical data from the same samples were revisited. The association of the palynofacies data with the total organic carbon, hydrogen index and sedimentological data made it possible to subdivide the studied section into nine units, called 1 to 9 , from the bottom to the top of the Tremembe Formation. Units 1, 3, 5, 7, and 9 represent low water depth phases in the lake, while units $2,4,6$, and 8 represent high water depth phases in the lake, with Unit 6 witnessing the period with thickest and most expanding water depth of the lake. The phases of low water depth in the lake have lower concentrations of fluorescent amorphous organic matter and predominance of Pediastrum algae over Botryococcus algae. In contrast to the phases of high water depth in the lake, with higher concentrations of fluorescent amorphous organic matter and predominance of Botryococcus algae over Pediastrum algae. In addition to contributing to the knowledge of the stratigraphic distribution of the microscopic characteristics of organic matter along the upper part of the Tremembé Formation in the central region of the Taubaté Basin, the new data constitute important paleoenvironmental indicators.

Keywords: Taubaté Basin, Tremembé Formation, palynofacies. 


\section{INTRODUÇÃO}

A palinofácies representa uma interpretação geológica do material orgânico sedimentar, seu estudo está intimamente ligado às interpretações sedimentológicas e reflete os ambientes e o clima à época de deposição (Tyson, 1995). No caso da aplicação no Oligoceno da Bacia de Taubaté (Figura 1), e excetuando os dados referidos em trabalhos não publicados, destacam-se dois trabalhos (CHAGAS et al., 2009; MENDONÇA FILHO et al., 2010), realizados de forma sistemática nos sedimentos pelíticos lacustres ricos em matéria orgânica da Formação Tremembé. Considerando a grande importância desses estudos e visando contribuir para o entendimento de como a parte superior da Formação Tremembé evoluiu em termos de tipos de matéria orgânica e de paleoambiente, são aqui apresentados novos dados de palinofácies e correlacionados com dados sedimentológicos e geoquímicos.

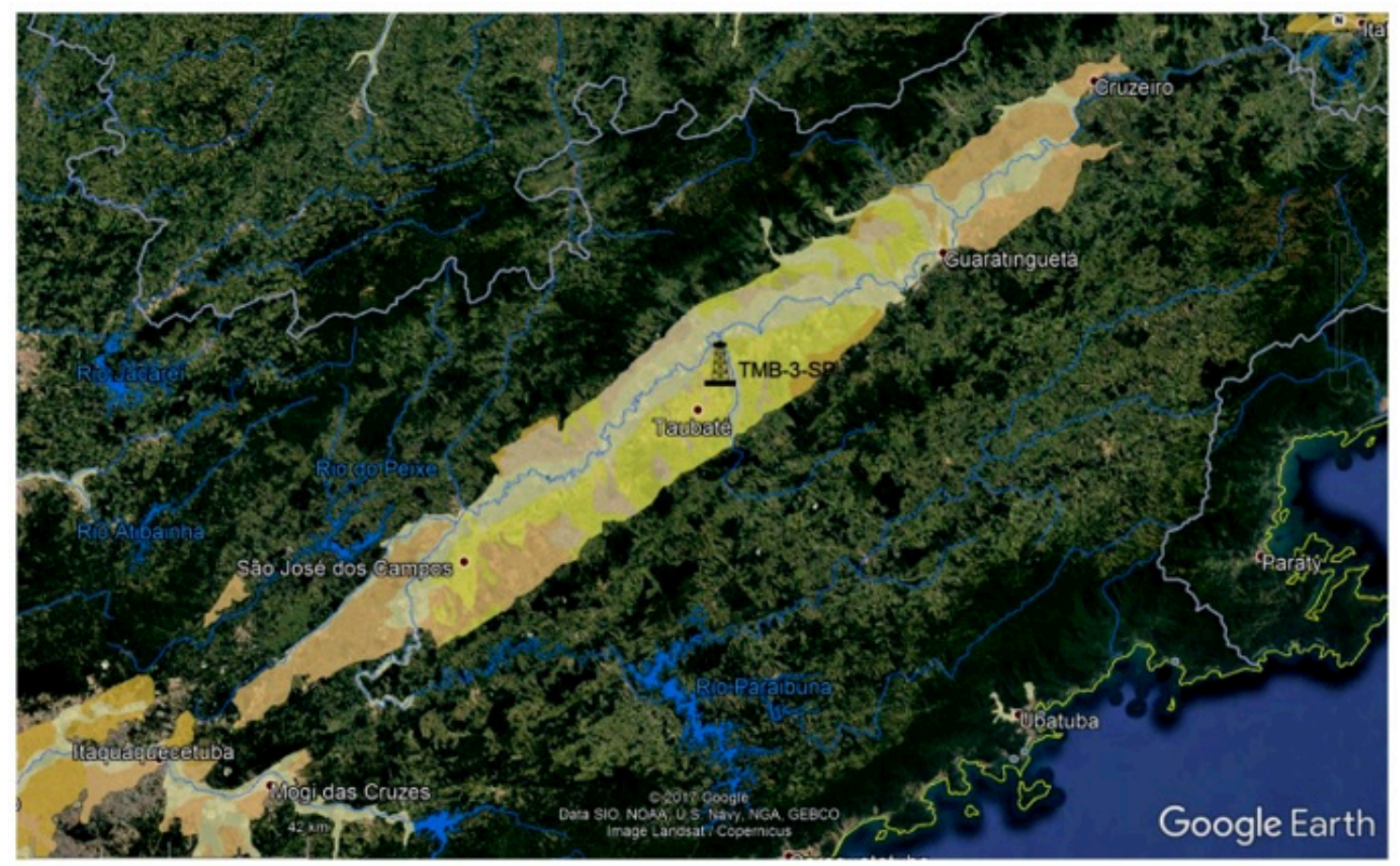

Figura 1 Localização do poço TMB-3-SP na região central da Bacia de Taubaté.

\section{MATERIAIS E MÉTODOS}

Para o estudo foi selecionado o poço TMB3-SP, testemunhado na parte superior da Formação Tremembé na região central da Bacia de Taubaté, no Estado de São Paulo, no Município de Tremembé (Figura 1). Este poço foi perfurado em 2014 no âmbito do Projeto INCT de Óleo e Gás - Jazidas Não Convencionais (INOG), sediado na UERJ e financiado pelo $\mathrm{CNPq}$ e FAPERJ. Foram analisadas palinofácies de 20 amostras e revisitados dados sedimentológicos e geoquímicos (carbono orgânico total - COT e índice de hidrogênio - IH) de 21 amostras obtidos de Setta et al. (2020). As litologias amostradas correspondem a argilitos verdes maciços (amostras $107 \mathrm{~m}, 79,90 \mathrm{~m}, 54,40 \mathrm{~m} \mathrm{e}$ $25,20 \mathrm{~m})$, folhelhos cinza médio com laminação incipiente (amostras 98,95 m e $14,80 \mathrm{~m}$ ), folhelhos cinza escuro a pretos laminados (amostras 89,95 m, 81,30 m, 70,70 m, $60,30 \mathrm{~m}, 56,30 \mathrm{~m}, 40,10 \mathrm{~m}, 36,50 \mathrm{~m}, 34,40$ $\mathrm{m}, 30,40 \mathrm{~m}$ e $20,40 \mathrm{~m}$ ) e folhelhos pretos papiráceos (amostras 49,20 m, 47,00 m, 38,10 $\mathrm{m}, 35,70 \mathrm{~m}$ e $32,80 \mathrm{~m}$ ).

As lâminas palinofaciológicas foram preparadas de acordo com os procedimentos descritos por Tyson (1995). As amostras foram fragmentadas em tamanhos inferiores a $05 \mathrm{~mm}$ e, posteriormente, acidificadas com ácido clorídrico e fluorídrico para eliminação dos carbonatos e silicatos, respectivamente. A matéria orgânica separada por flotação utilizando-se cloreto de zinco, foi, então, concentrada em lâminas de vidro para as 
análises em microscópio ótico sob luz branca transmitida e luz azul incidente. As partículas orgânicas foram classificadas segundo sistema proposto por Tyson (1995). As abundâncias relativas dos grupos e subgrupos da matéria orgânica foram obtidas pela contagem de 300 partículas com tamanho superior a $10 \mu \mathrm{m}$. Após a contagem dos componentes orgânicos,

\section{RESULTADOS E DISCUSSÃO}

A associação dos dados de palinofácies (Tabela 1) com os dados de COT, IH e sedimentológicos possibilitou subdividir a seção estudada em nove unidades,

\subsection{UNIDADE 1}

É representada pela amostra $107 \mathrm{~m}$. É caracterizada por uma mistura entre microplâncton de água doce com fluorescência fraca a intensa (50 \% da matéria orgânica total) e matéria orgânica amorfa com fluorescência fraca $(40 \%$ da matéria orgânica total). A presença de esporomorfos com florescência fraca $(10 \%$ da matéria orgânica total) se verifica em proporção relativa complementar (Tabela 1 e Figuras 2 e 3G-H).

A predominância de matéria orgânica com fluorescência fraca, juntamente com o teor de COT de $1 \%$ e valor do $\mathrm{IH}$ de $330 \mathrm{mg} \mathrm{HC} / \mathrm{g}$ COT (Figuras 2 e 3G-H), indicam, segundo Jones (1987) e Tyson (1995), um ambiente disóxico.

Entre o microplâncton de água doce, as

\subsection{UNIDADE 2}

Corresponde às amostras 98,95 m, 89,95 m e $81,30 \mathrm{~m}$. É caracterizada pela predominância de matéria orgânica amorfa com fluorescência fraca a moderada (59 a $72 \%$ da matéria orgânica total). Subordinadamente, foram observados microplâncton de água doce com fluorescência intensa (10 a $32 \%$ da matéria orgânica total), esporomorfos com fluorescência intensa ( 9 a $17 \%$ da matéria orgânica total) e fitoclastos não opacos (0 a 1 $\%$ da matéria orgânica total) (Tabela $1 \mathrm{e}$ Figuras 2 e 3E-F).

Quando comparado à Unidade 1, a maior proporção relativa de matéria orgânica amorfa os valores absolutos foram recalculados para valores percentuais e normalizados a $100 \%$. A preparação e leitura das lâminas palinofaciológicas foram efetuadas no Laboratório de Palinofácies e Fácies Orgânicas (LAFO) do Departamento de Geologia da Universidade Federal do Rio de Janeiro (UFRJ).

denominadas de 1 a 9, da base para o topo da parte superior da Formação Tremembé (Figura 2).

algas do gênero Pediastrum (35\% da matéria orgânica total) predominam sobre as algas do gênero Botryococcus $(15 \%$ da matéria orgânica total) (Tabela 1 e Figuras 2 e 3G-H). De acordo com Chagas et al. (2009) e Mendonça Filho et al. (2010), a predominância de algas do gênero Pediastrum sobre as algas do gênero Botryococcus constitui evidência de nível alto do lago. No entanto, a litofácies da amostra $107 \mathrm{~m}$, argilito verde maciço, não indica a condição de nível alto do lago, mas sim nível baixo do lago, com exposição subaérea, como descrito por Riccomini et al. (2004), Torres-Ribeiro e Borghi (2007), Bergamaschi et al. (2010) e Setta et al. (2012). Assim, esta unidade corresponde a uma fase de lâmina de água baixa no lago.

mais fluorescente e os maiores valores de COT (2 a $13 \%)$ e IH (290 a $645 \mathrm{mg} \mathrm{HC} / \mathrm{g} \mathrm{COT})$ (Figuras 2 e 3E-H), indicam, de acordo com Jones (1987) e Tyson (1995), que as amostra da Unidade 2 foram depositadas em ambiente mais redutor, disóxico a anóxico. As litofácies das amostras da Unidade 2, folhelhos cinza médio com laminação incipiente a pretos laminados, também podem ser consideradas indicadores de um ambiente disóxico a anóxico e do aumento da profundidade da lâmina de água, como postulado por Riccomini et al. (2004), Torres-Ribeiro e Borghi (2007), Bergamaschi et al. (2010), Setta et al. (2012). 


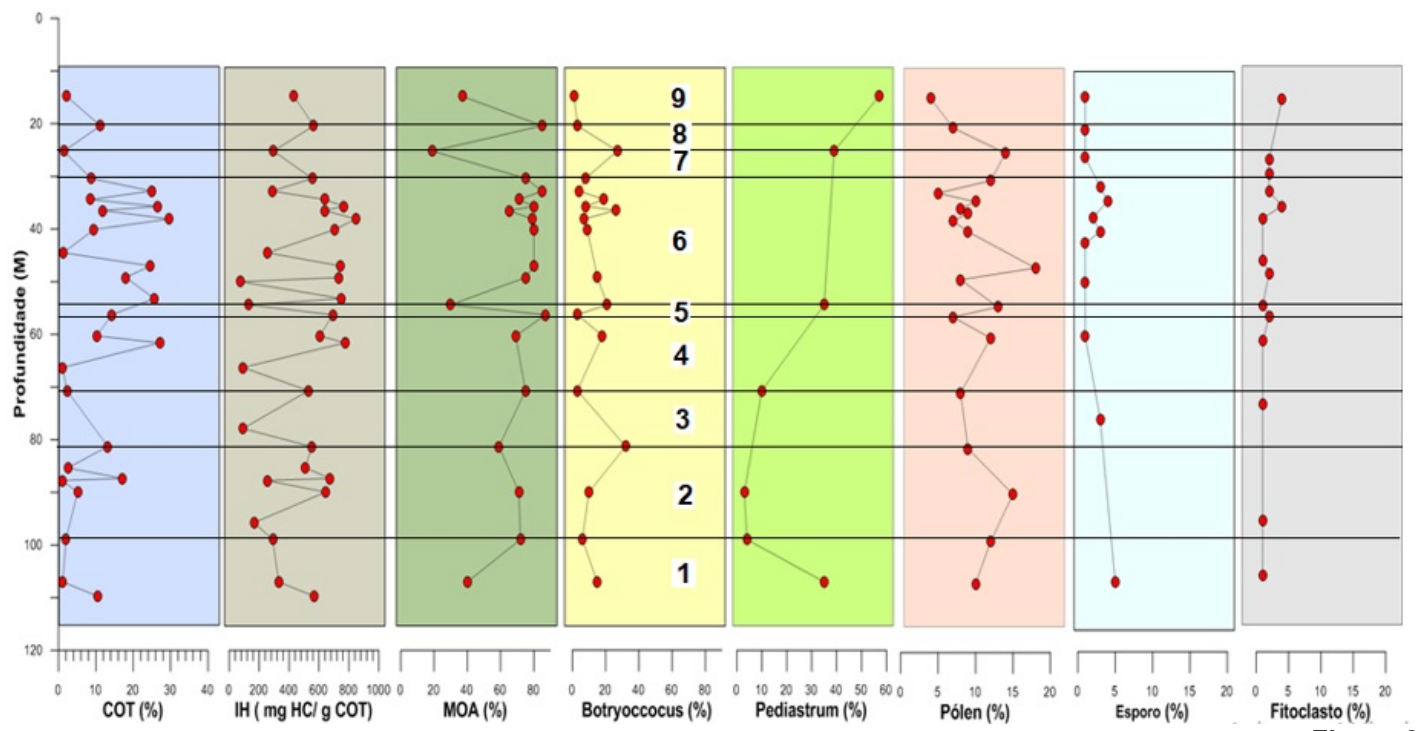

Dados de geoquímica orgânica e de palinofácies da parte superior da Formação Tremembé no poço TMB-3-SP. Também estão ilustradas as unidades (1 a 9) subdivididas com base na variação organofaciológica. COT - carbono orgânico total; IH -

índice de hidrogênio; MOA - matéria orgânica amorfa. Dados de palinofácies deste estudo e de geoquímica orgânica de Setta et al. (2020).

Ainda em relação à Unidade 1, outra característica da palinofácies que se modifica é a predominância das algas do gênero Botryococcus (6 a $32 \%$ da matéria orgânica total) sobre as algas do gênero Pediastrum (3 a $4 \%$ da matéria orgânica total) (Tabela 1 e Figuras 2 e 3E-H). Como as amostras da Unidade 2 foram depositadas em nível mais alto do lago em relação às da Unidade 1 , o

\subsection{UNIDADE 3}

É representada pela amostra 79,90 m. Possui um teor de COT de $0,05 \%$ pelo que a sua palinofácies não foi analisada (Figura 2). Entretanto, o seu baixo teor de COT e sua litofácies, argilito verde maciço, indicam, segundo Jones (1987), um ambiente muito óxico e uma diminuição da profundidade da

\subsection{UNIDADE 4}

Engloba as amostras $70,70 \mathrm{~m}, 60,30 \mathrm{~m} \mathrm{e}$ $56,30 \mathrm{~m}$. É caracterizada pelo domínio de matéria orgânica amorfa com fluorescência aumento da proporção de algas do gênero Botryococcus em relação às algas do gênero Pediastrum está relacionado ao aumento da profundidade da lâmina de água do lago e não à diminuição dessa profundidade como proposto por Chagas et al. (2009) e Mendonça Filho et al. (2010). Esta unidade corresponde, portanto, a uma fase de lâmina de água alta no lago.

lâmina de água do lago, como descrito por Riccomini et al. (2004), Torres-Ribeiro e Borghi (2007), Bergamaschi et al. (2010) e Setta et al. (2012); condições deposicionais estas diferentes das da Unidade 2. A Unidade 3 representa, assim, uma nova fase de lâmina de água baixa no lago.

moderada a intensa (69 a $87 \%$ da matéria orgânica total). A presença de micro-plâncton de água doce com fluorescência 


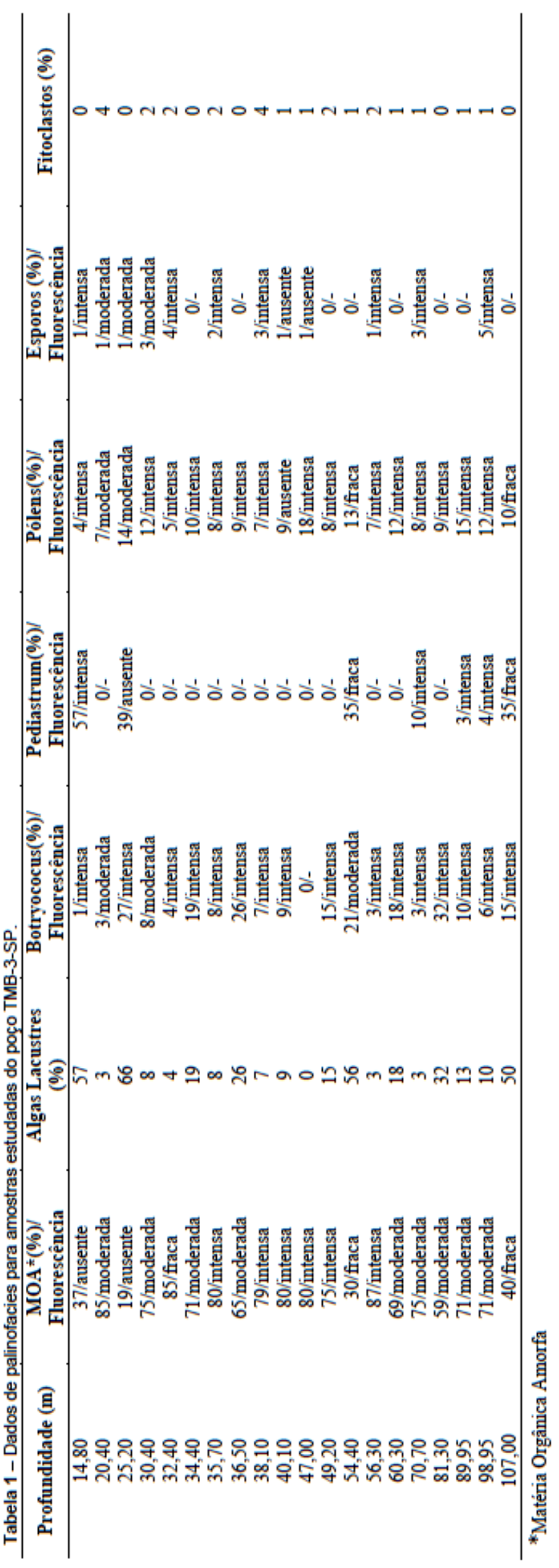


intensa (3 a $18 \%$ da matéria orgânica total), esporomorfos com fluorescência intensa ( 8 a $12 \%$ da matéria orgânica total) e fitoclastos não opacos (1 a $2 \%$ da matéria orgânica total) se verificam em proporções relativas complementares (Tabela 1 e Figuras 2 e $3 \mathrm{~A}$ D).

A predominância de matéria orgânica amorfa com fluorescência moderada a intensa, juntamente com os teores de COT entre 2 e 14 $\%$ e valores do $\mathrm{IH}$ entre 530 e $690 \mathrm{mg} \mathrm{HC} / \mathrm{g}$ COT (Figuras 2 e 3A-D), indicam, de acordo com Jones (1987) e Tyson (1995), um ambiente disóxico-anóxico, portanto redutor, diferentemente do Conjunto 3. A sua litofácies,

\subsection{UNIDADE 5}

É representada pela amostra dos $54,40 \mathrm{~m}$. É caracterizada por uma mistura entre microplâncton de água doce com fluorescência fraca a moderada (56 \% da matéria orgânica total) e matéria orgânica amorfa com fluorescência fraca (30\% da matéria orgânica total). Subordinadamente, foram observados esporomorfos com fluorescência fraca (13\% da matéria orgânica total) e fitoclastos não opacos ( $1 \%$ da matéria orgânica total). Entre o microplâncton de água doce, as algas do gênero Pediastrum (35 \% da matéria orgânica total) predominam sobre as algas do gênero Botryococcus (21\% da matéria orgânica total) (Tabela 1 e Figuras 2 e 4F-G).

\subsection{UNIDADE 6}

Inclui as amostras 49,20 m, 47,00 m, 40,10 m, 38,10 m, 36,50 m, 35,70 m, 34,40 m, 38,80 $\mathrm{m}$ e $30,40 \mathrm{~m}$. É caracterizada pela predominância de matéria orgânica amorfa com fluorescência moderada a intensa (65 a 85 $\%$ da matéria orgânica total). A presença de microplâncton de água doce com florescência moderada a intensa ( 0 a $26 \%$ da matéria orgânica total), esporomorfos com fluorescência ausente a intensa (8 a $19 \%$ da matéria orgânica total) e fitoclastos não opacos

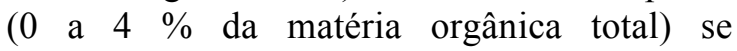
verificam em proporções relativas complementares. O microplâncton de água doce é exclusivamente composto de algas do gênero Botryococcus (Tabela 1 e Figuras 2 e 4D-E).

Exibe as maiores proporções relativas de matéria orgânica amorfa com fluorescência intensa e os maiores valores de COT (9 a 30 folhelhos cinza escuro a pretos laminados, também pode ser considerada, segundo Riccomini et al. (2004), Torres-Ribeiro e Borghi (2007), Bergamaschi et al. (2010) e Setta et al. (2012), indicador de um ambiente disóxico a anóxico e do aumento da profundidade da lâmina de água do lago, quando comparada à Unidade 3.

À semelhança da Unidade 2, também depositada em nível alto do lago, as algas do gênero Botryococcus (3 a $18 \%$ da matéria orgânica total) predominam sobre as algas do gênero Pediastrum ( 0 a $10 \%$ da matéria orgânica total) (Tabela 1 e Figuras 2 e 3A-D).

Quando comparada à Unidade 4, a diminuição da proporção relativa de matéria orgânica fluorescente, o aumento da proporção das algas do gênero Pediastrum em relação às algas do gênero Botryococcus, os valores menores de COT e IH $(0,6 \%$ e $128 \mathrm{mg} \mathrm{HC} / \mathrm{g}$ COT, respectivamente) (Tabela 1 e Figuras 2 e 4F-I) e a distinta litofácies, argilito verde maciço, indicam, de acordo com Jones (1987), Tyson (1995), Riccomini et al. (2004), TorresRibeiro e Borghi (2007), Bergamaschi et al. (2010) e Setta et al. (2012), a mudança de um ambiente disóxico-anóxico para óxico e a diminuição da profundidade da lâmina de água do lago; constituindo-se, assim, uma nova fase de lâmina de água baixa no lago.

\%) e IH (550 a $850 \mathrm{mg} \mathrm{HC/g} \mathrm{COT)} \mathrm{de} \mathrm{toda} \mathrm{a}$ seção estudada (Tabela 1 e Figuras 2, 3A-H e 4A-I), indicando, segundo Jones (1987) e Tyson (1995), o período onde as condições foram mais redutores (ambiente anóxico). A presença de folhelhos pretos papiráceos, ausentes nos outros conjuntos, intercalados com folhelhos pretos laminados, não só reforça, de acordo com Riccomini et al. (2004), Torres-Ribeiro e Borghi (2007), Bergamaschi et al. (2010) e Setta et al. (2012), as evidências de que as amostras da Unidade 6 foram depositados em ambiente anóxico bem como indica o período com lâmina de água mais espessa e de maior expansão do lago. Estas condições paleoambientais terão possibilitado a proliferação de algas do gênero Botryococcus. Segundo Chagas et al. (2009) e Mendonça Filho et al. (2010), algas do gênero Botryococcus são abundantes quando a lâmina 
de água está baixa e a salinidade mais elevada. Os dados obtidos neste estudo, bem como o valor isotópico do carbono orgânico (- 28 \%o) medido, por Soldan et al. (1988), em uma amostra de folhelho preto papiráceo da Formação Tremembé com predominância de matéria orgânica amorfa (95\% da matéria orgânica total) e domínio de algas do gênero Botryococcus entre os palinomorfos (47 \%), não permitem adotar o modelo proposto por Chagas et al. (2009) e Mendonça Filho et al. (2010). Sugere-se, desta forma, que palinofácies com as características da Unidade 6 representam fase de lâmina de água alta no lago, em vez de fase de lâmina de água baixa no lago como postulado por Chagas et al. (2009) e Mendonça Filho et al. (2010).

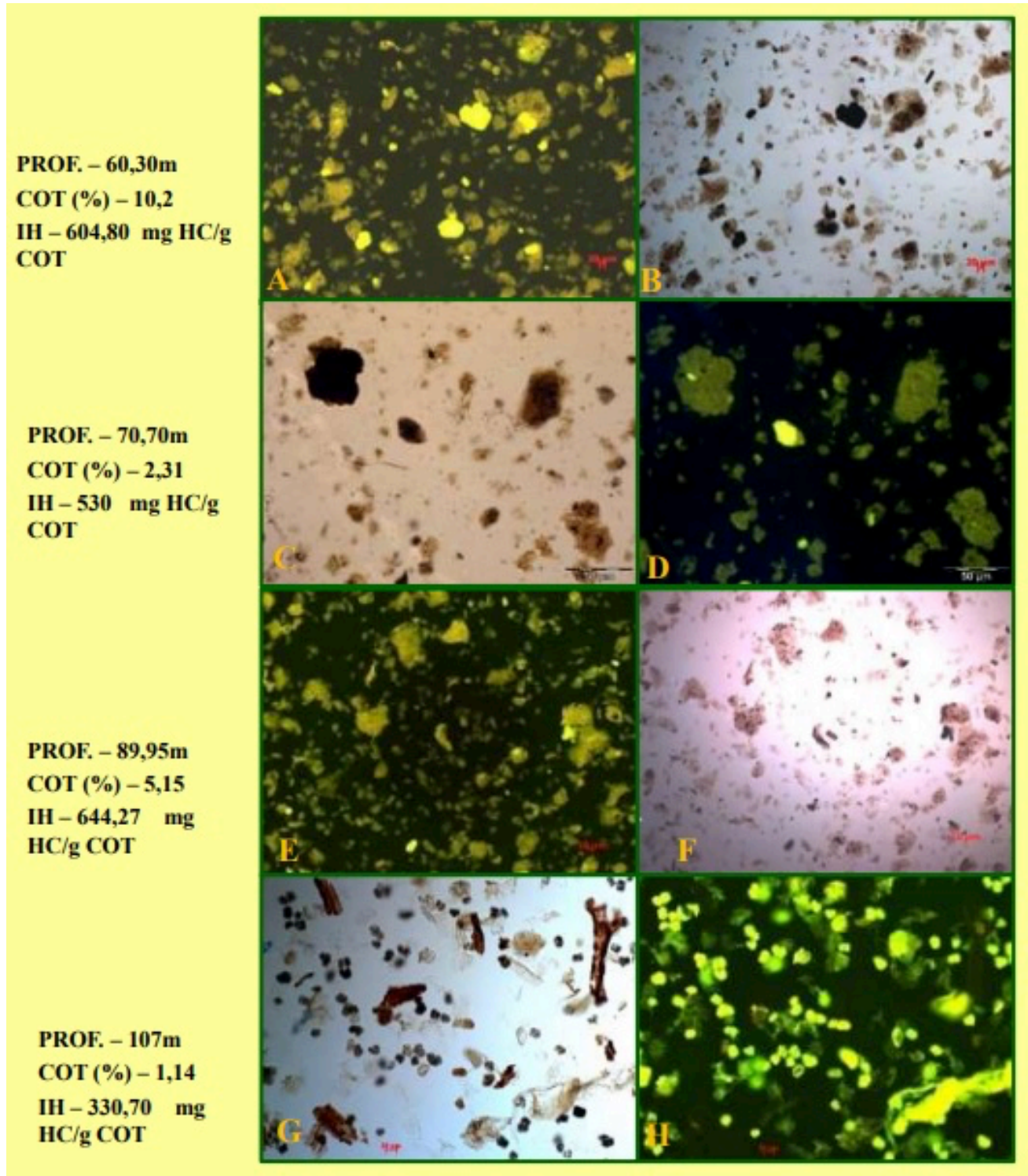

Figura 3

Palinofácies recuperadas em argilito verde maciço da Unidade $1(\mathrm{G} \mathrm{e} \mathrm{H})$, folhelho preto laminado da Unidade 2 ( $\mathrm{E}$ e $\mathrm{F}$ ), folhelho cinza escuro laminado ( $C$ e D) e folhelho preto laminado ( $A$ e B) da Unidade 4. Também estão ilustrados para cada amostra os dados de carbono orgânico total (COT) e índice de hidrogênio (IH). 


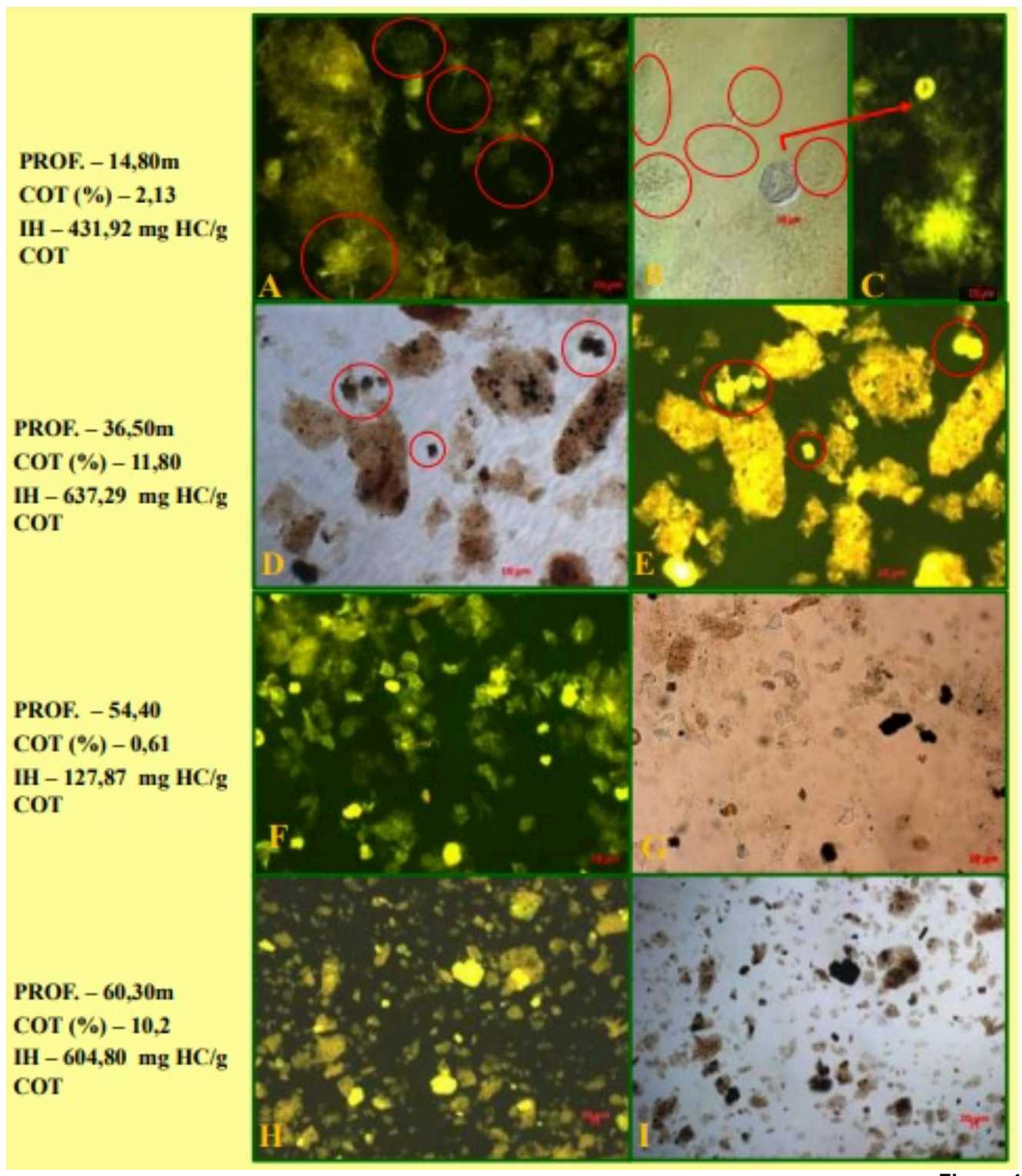

Figura 4

Palinofácies recuperadas em folhelho preto laminado da Unidade 4 ( $\mathrm{H} \mathrm{e} \mathrm{I}$ ), argilito verde maciço da Unidade 5 ( $F$ e $G$ ), folhelho preto laminado da Unidade 6 (D e E) e folhelho cinza médio com laminação incipiente da Unidade 9 (A, B e C). Os círculos e seta a vermelho destacam algas dos gêneros Botryococcus (D e E) e Pediastrum (A, B e C). Também estão ilustrados para cada amostra os dados de carbono orgânico total (COT) e índice de hidrogênio (IH).

\subsection{UNIDADE 7}

Compreende a amostra 25,20 m. É caracterizada pela predominância de microplâncton de água doce com fluorescência ausente a intensa $(68 \%$ da matéria orgânica total. A presença de matéria orgânica amorfa sem fluorescência (19 \% da matéria orgânica total) e esporomorfos com florescência moderada ( $15 \%$ da matéria orgânica total) se verificam em proporções relativas complementares. Entre o microplâncton de água doce, as algas do gênero Pediastrum (39 da matéria orgânica total) predominam sobre as algas do gênero Botryococcus $(27 \%$ da matéria orgânica total) (Tabela 1 e Figura 2). Estas características da palinofácies, juntamente com a litofácies, argilito verde maciço, e os valores de COT de 1,5 e IH de $295 \mathrm{HC} / \mathrm{g}$ COT (Figura 2), indicam, de acordo com Jones (1987), Tyson (1995), Riccomini et al. (2004), Torres-Ribeiro e Borghi (2007), Bergamaschi et al. (2010) e Setta et al. (2012), o retorno para condições de fundo melhor oxigenadas (ambiente disóxico) e uma nova fase de diminuição do nível do lago. 


\subsection{UNIDADE 8}

É representada pela amostra 20,40 m, cujo a litofácies é folhelho preto laminado. A predominância de matéria orgânica amorfa com fluorescência moderada ( $85 \%$ da matéria orgânica total), a presença exclusiva de algas do gênero Botryococcus no microplâncton de água doce ( $3 \%$ da matéria orgânica total) (Tabela 1), a litofácies e os valores de COT de

\subsection{UNIDADE 9}

É constituída pela amostra $14,80 \mathrm{~m}$. É caracterizada por uma mistura entre microplâncton de água doce com fluorescência intensa (58 \% da matéria orgânica total) e matéria orgânica amorfa sem fluorescência (37 $\%$ da matéria orgânica total). Subordinadamente, foram observados esporomorfos com fluorescência intensa (5\% da matéria orgânica total). Entre o microplâncton de água doce, as algas do gênero Pediastrum (57 \% da matéria orgânica total) predominam sobre as algas do gênero Botryococcus (1\% da matéria orgânica total) (Tabela 1 e Figuras 2 e 4A-C).

\section{CONCLUSÕES}

Na parte superior da Formação Tremembé na região central da Bacia de Taubaté, foram identificadas nove unidades. Cada uma delas apresenta características microscópicas e geoquímicas próprias, refletindo modificações na composição e concentração da matéria orgânica, oriundas das variações químicas e físicas ocorridas no meio deposicional, relacionadas com as flutuações do nível de água do lago. As unidades 1, 3, 5, 7 e 9 representam fases de lâmina de água baixa no lago, enquanto que as unidades $2,4,6$ e 8 correspondem a fases de lâmina de água alta no lago, testemunhando a Unidade 6 o período com lâmina de água mais espessa e de maior

\section{AGRADECIMENTOS}

Ao Projeto "INOG", patrocinado pelo $\mathrm{CNPq}$ e FAPERJ, pelo apoio à pesquisa, e ao LAFO/UFRJ pela preparação das lâminas palinofaciológicas e infraestrutura. Elayne Maas e Marco Brito também agradecem, respectivamente, à CAPES pela bolsa de
$11 \%$ e IH de $560 \mathrm{mg} \mathrm{HC} / \mathrm{g}$ COT (Figura 2) são características, segundo Jones (1987), Tyson (1995), Riccomini et al. (2004), TorresRibeiro e Borghi (2007), Bergamaschi et al. (2010) e Setta et al. (2012), de um ambiente disóxico-anóxico e de um novo episódio de aumento da profundidade da lâmina de água.

Quando comparada à Unidade 8, a diminuição da proporção relativa de matéria orgânica amorfa fluorescente, o aumento da proporção das algas do gênero Pediastrum em relação às algas do gênero Botryococcus (Tabela 1), os valores menores de COT e IH (2 $\%$ e $430 \mathrm{mg} \mathrm{HC} / \mathrm{g} \mathrm{COT}$, respectivamente) (Figuras 2 e 4A-C) e a distinta litofácies, folhelho cinza médio com laminação incipiente, indicam, de acordo com Jones (1987), Tyson (1995), Riccomini et al. (2004), Torres-Ribeiro e Borghi (2007), Bergamaschi et al. (2010) e Setta et al. (2012), a mudança de um ambiente disóxico-anóxico para disóxico e a diminuição da profundidade da lâmina de água do lago.

expansão do lago. As fases de lâmina de água baixa no lago, possuem menores concentrações de matéria orgânica amorfa fluorescente e predomínio de algas do gênero Pediastrum sobre algas do gênero Botryococcus. Em contraste com as fases de lâmina de água alta no lago, com maiores concentrações de matéria orgânica amorfa fluorescente e predomínio de algas do gênero Botryococcus sobre algas do gênero Pediastrum. Os novos dados de palinofácies contribuem para o entendimento de como a parte superior da Formação Tremembé evoluiu em termos de tipos de matéria orgânica e de paleoambiente.

doutorado e FUSP pela bolsa de pesquisa, no âmbito do Projeto "REDE GASBRAS", patrocinado pela FINEP. Os autores agradecem também o trabalho de dois revisores anônimos, na análise do artigo. 


\section{REFERÊNCIAS}

BERGAMASCHI, S., RODRIGUES, R., PEREIRA, E., 2010. Avaliação geoquímica dos folhelhos betuminosos da Formação Tremembé, Bacia de Taubaté, Brasil, In: X Congresso de Geoquímica dos Países de Língua Portuguesa/XVI Semana de Geoquímica, Memórias 14, pp. 263-272.

CHAGAS, R.B.A., MENDONÇA FILHO, J.G., MENDONÇA, J.O., MENEZES, T.R., 2009. Caracterização palinofaciológica de uma sucessão sedimentar Oligocênica da Formação Tremembé, Bacia de Taubaté. Revista Brasileira de Paleontologia 12, 257 266.

JONES, R.W., 1987. Organic Facies. In: Brooks, J., WELTE, D. (eds.), Advances in Petroleum Geochemistry. Academic Press 2, pp. 1-90.

MENDONÇA FILHO, J.G., CHAGAS, R.B.A., MENEZES, T.R., MENDONÇA, J.O., DA SILVA, F.S., SABADINISANTOS, E., 2010. Organic facies of the Oligocene lacustrine system in the Cenozoic Taubaté basin, Southern Brazil. International Journal of Coal Geology 84, 166-178.

RICCOMINI, C., SANT'ANNA, L.G., FERRARI, A.L., 2004. Evolução geológica do Rift Continental do Sudeste do Brasil, In: Mantesso Neto, V., Bartorelli, A., Carneiro, C.D.R., Brito Neves, B.B. (org.), Geologia do Continente Sul-Americano: Evolução da Obra de Fernando Flávio Marques de Almeida. Beca, São Paulo, pp. 383-405.
SETTA, F., BERGAMASCHI, S., RODRIGUES, R., JONES, C., CHAVES, H., BRITO, M., PEREIRA, E., 2020. The volumetric potential assessment of the oil shales of Tremembé Formation, Taubaté Basin, Brazil. Journal of Petroleum Exploration and Production Technology 10, 1835-1848.

SETTA, F., BERGAMASCHI, S., RODRIGUES, R., PEREIRA, E., CHAVES, H.A.F., 2012. Avaliação de jazidas não convencionais - folhelhos betuminosos da Formação Tremembé, Bacia de Taubaté, In: Anais da Rio Oil \& Gas Expo and Conference 2012, Instituto Brasileiro de Petróleo, Gás e Biocombustíveis - IBP, Rio de Janeiro, Brasil.

SOLDAN, A.L., SANTOS NETO, E.V., CERQUEIRA, J.R., CONCHA, F.J.M., BRANCO, V.A.C., ARAI, M., 1988. Hidropirólise: uma nova ferramenta para o estudo do processo de maturação. Boletim de Geociências da Petrobras 2, 65-76.

TORRES-RIBEIRO, M., BORGHI, L., 2007. $\mathrm{O}$ uso de microfácies sedimentares na caracterização de potenciais rochas geradoras de um sistema lacustre paleogênico na Bacia de Taubaté, In: Anais do $4^{\circ}$ PDPETRO - Congresso Brasileiro de P\&D em Petróleo e Gás, ABPG, Campinas, Brasil.

TYSON, R.V., 1995. Sedimentary Organic Matter. Organic facies and palynofacies, Chapman \& Hall, Londres, 615 p. 